\title{
Review Article: Failures to Cure and Diagnose Cervical Cancer
}

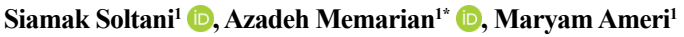

1. Department of Forensic \& Legal Medicine, Faculty of Medicine, Iran University of Medical Sciences, Tehran, Iran.

\begin{tabular}{|c|c|}
\hline $\begin{array}{l}\text { Use vourd device to scan } \\
\text { and read the article online }\end{array}$ & Citation: Soltani S, Memarian A, Ameri M. Failures to Cure and Diagnose Cervical Cancer. International Journal of Medical \\
\hline 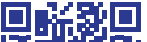 & Toxicology and Forensic Medicine. 2019; 9(4):175-180. https://doi.org/10.32598/ijmtfm.v9i4.25971 \\
\hline 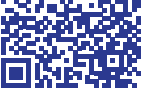 & doij https://doi.org/10.32598/ijmtfm.v9i4.25971 \\
\hline
\end{tabular}

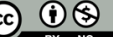

Article info:

Received: 10 Apr 2019

First Revision: 27 Apr 2019

Accepted: 08 Aug 2019

Published: 01 Oct 2019

\section{ABSTRACT}

Background: Cervical cancer is one of the most common cancers in developing countries and the second most common cancer in women worldwide. Using the screening test, cancer can be detected in the early stages and, thus, mortality will be reduced. Also, the early detection of cervical cancer could affect survival rate and time. But, the diagnostic and therapeutic methods of this disease are usually accompanied by errors that deduct the success rate.

Methods: In this study, a variety of common errors in the detection and treatment of cervical cancer were investigated by reviewing and evaluating scientific resources.

Results: Studies show the different medical failures during sampling, preparation, review, and interpretation of the sample. On the other hand, inappropriate operation and errors in the treatment pathway are common errors after diagnosis. Because of the types of these errors, preparing the information of papers investigating the possible types of errors and observing accuracy will play a significant role in reducing the failures.

Conclusion: Because of the fact that cervical cancer is fully curable with proper and timely diagnosis, the early diagnosis is important and it is the responsibility of doctors, pathologists, and surgeons in this area. Therefore, monitoring and preventing errors in the diagnosis and treatment is directly associated with a reduction in the mortality rate of the disease.
Cervix uteri, Neoplasm, Malpractice

\section{Introduction}

I

ncreasing medical errors is a general concern for health policymakers. Based on the latest published statistics, medical errors are the eighth cause of death in the world $[1,2]$. A study in the
United States shows that every year about 98000 people are dying as a result of medical errors [3].

Medical errors are made by misconduct in planning or executing, which effectively or potentially cause an unwanted result. Some errors or mistakes made by the medical team can lead to injury, including diagnostic er-

\section{* Corresponding Author:}

Azadeh Memarian, MD.

Address: Department of Forensic \& Legal Medicine, Faculty of Medicine, Iran University of Medical Sciences, Tehran, Iran.

Tel: +98 (21) 66551201

E-mail: memarian.a@iums.ac.ir 
rors, mistakes in prescribing drugs and therapeutic procedures, mistakes in the surgical procedure, mistakes in the use of technology and equipment, and mistakes in the interpretation of paraclinical tests [4].

Medical misdiagnosis can completely distort the treatment pathway; thus, sometimes the patient loses the opportunity for treatment because of a misdiagnosis and, therefore, the treatment steps go much harder than before. It is worth noting that false medical diagnosis is not the only product of a person's mistake and there are many factors involved in [5].

Cervical cancer is the third leading malignancy in the developed countries and the second common malignancy in women throughout the world, which affects the lower part of the uterus, namely the cervix $[1,2]$.

Countries that provide the Papanicolaou smear test as a part of systematic cancer screening programs have been able to reduce the incidence and mortality of this disease [4]; owing to the successful screening programs, the incidence of malignant cervical cancer has reduced by $70 \%$ [6]. In the developed countries, cervical cytology programs, including the screening of sexually-active women annually or once every 2 to 5 years have resulted in a good controlling in cervical cancer incidence and mortality $[7,8]$.

In the Pap smear test, cells taken from the cervix are microscopically examined. The upper age limit for the effectivity of this screening is not known [9]. However, elderly women with several recent normal Pap smears are known to be at extremely low risk of cervical cancer [9].

This test enables the detection of both cervical dysplasia and cervical cancer. However, cervical cancer may not be detected when an error is committed by the physician or technician in performing and interpreting Pap smear tests, or the patients' important medical history is inaccurately reviewed or ignored [8].

The main principle in the prevention of cervical cancer is the cessation of the proliferation of malignant cells through proper screening and confirmatory diagnostic tests (if required). Hence, at least theoretically, cervical cancer can be said to be a preventable disease.

Moreover, since cervical malignant cells grow slowly, the non-detection of cancer or its early stage by the physician is inexcusable [10].
Although Pap smear is commonly performed by a primary care physician or a gynecologist, the results are often interpreted by a laboratory technician; since they are not physicians and have a huge workload, there is a likelihood of declaring a false-negative test result. Accordingly, the American Medical Association has estimated that up to $30 \%$ of Pap smear tests are likely to be false [2].

According to this notion, cervical cancer screening and management guidelines released more complex guidelines in 2012, incorporated new materials, which recommend different screening intervals for women based on the severity of the preceding cytology results, human papillomavirus testing, medical conditions (e.g. immunosuppression), and age [11].

On the other hand, studies show that some medical errors occur in the treatment stage since it has been illustrated that $4 \%$ to $15 \%$ of invasive cervical cancers are found after an inappropriate hysterectomy $[12,13]$

The present article reviews the data obtained from the articles and reported cases and discusses errors committed in the diagnosis and treatment of cervical cancer.

\section{Materials and Methods}

The latest research and review articles, case reports, guidelines, and evidence were selected and reviewed, using the following keywords: "cervical cancer, cervix, diagnosis, error, negligence, surgery, and their equivalents". The irrelevant articles were excluded after primary review and the selected articles were classified based on the type and date of publication. Finally, 25 articles conducted from 1986 to 2017 were used in the present study.

\section{Results}

The cytologist, laboratory technician, or gynecologist have the main responsibility of examining the patient's samples for diagnosing and targeting the treatment of the disease. The cytologist that examines Pap smear slides, in fact, enters the patient's private world and has a huge responsibility for her life. An error may be catastrophic at this stage, which affects not only the patient but also her family and relatives [14].

\section{Discussion}

\section{Errors in screening}

The lack of screening or any kind of mistake in screening for cervical cancer leads to the treatment failure of 
this type of cancer. According to statistics, 54\% of women with cervical cancer had been screened and $42 \%$ had no history of screening [4].

The accuracy of a screening test is related to 4 indices, including sensitivity, specificity, positive predictive value, and negative predictive value [9].

Errors in the diagnosis of cervical cancer may occur in the Pap smear test and its interpretation so that a large proportion of such tests with normal results are classed as false-negative. Research indicates that $29.3 \%$ of women with cervical cancer had received false-negative results a few years ago [15]. The wrong diagnosis by a clinical pathologist could lead to a delayed or inappropriate therapy that may result in legal action from the patient, who suffered from outcomes [15].

In some cases, the quality of tests conducted in different hospitals or regions, and also the sample size cause errors in diagnosis [2]. Previous studies show that errors in sampling, interpretation of samples, and ultimately, diagnosis lead to false results (Table 1).

Studies show that the cytology of malignant cells is to blame for $10 \%$ to $60 \%$ of the false-negative reports, and the remaining reports are concerned with errors in sam- pling, preparation (such as wrong labeling), and rapid progress of the disease [16].

According to Bahiraee, the most common Pap smear error occurs in the sample preparation stage by delayed fixing, which causes the sample to dry in the air [17].

In a new method, a liquid-based thin-layer slide is prepared for collecting and analyzing cytologic samples, using a brush or other collection instruments. Finally, the instrument is rinsed in a vial of liquid preservative. Evidence shows that this method is comparable to, and perhaps more sensitive than, standard Pap tests for the detection of significant abnormalities [9].

Errors attributed to cytology are divided into 1. Assessment errors, such as failure to find malignant cells in the patient's smear (when the number of malignant cells is small or when they are hidden by infectious cells); 2 . Diagnostic errors, such as errors in categorizing cells, when they are found for the first time and incorrect interpretation; 3. Various technical problems, such as inappropriate staining [17].

For example, when malignant cells are detected in reassessing a negative sample, the error is an assessment error, when malignant cells are not first detected usually because of their small size or small numbers and their pale nucleus.

Table 1. Cytological factors and human error leading to false-negative results

\begin{tabular}{|c|c|}
\hline The Causes of Errors & The Results of Errors \\
\hline \multirow{7}{*}{$\begin{array}{l}\text { Cytological factors leading to } \\
\text { false-negative results }\end{array}$} & The small number of samples in the smear \\
\hline & The small size of cells \\
\hline & $\begin{array}{l}\text { Cells with a pale nucleus } \\
\text { Leading to errors in interpretation } \\
\text { Leading to non-differentiation of malignant cells from squamous immature metaplasia cells } \\
\text { Making histiocytes indistinguishable from malignant cells }\end{array}$ \\
\hline & $\begin{array}{l}\text { Hyperchromatic groups of cells } \\
\text { leading to non-differentiation of these cells from atrophic, endometrial, etc. from malignant cells }\end{array}$ \\
\hline & $\begin{array}{l}\text { The presence of several types of tumor cells, } \\
\text { for example, adenocarcinoma, lymphoma, sarcoma, etc. }\end{array}$ \\
\hline & $\begin{array}{l}\text { Non-transparent sample } \\
\text { because of inflammation, blood, drying in the air, spoiling of the sample, etc. }\end{array}$ \\
\hline & Patient providing incomplete information \\
\hline \multirow{4}{*}{$\begin{array}{l}\text { The human error leading to } \\
\text { false-negative results }\end{array}$} & Cervix not in full view \\
\hline & Use of inappropriate sampling tools \\
\hline & Improper sampling (such as incomplete removal of cylindrical squamous epithelium) \\
\hline & Incorrect sample fixation \\
\hline
\end{tabular}


One of the reasons for a false negative report is the characteristics of the cancerous lesion. For example, some cancerous lesions reveal fewer detectable cells [14]. Additionally, the position and size of the lesion are also highly important. Sampling is even affected by the shape of cells and the quality of mucus [14]. Moreover, necrosis, inflammation, and hemorrhage can cause the dilution of cells and change the result. Since the invasive type of cervical cancer has these properties, false-negative results are more frequent with these types. Hence, false-negative reports are $20 \%$ for in situ cancers and $42 \%$ for the invasive type of cervical cancers. Identifying the certain types of tumors such as adenocarcinoma (which is clinically more important) is harder with a false-negative Pap smear. Lymphomas and sarcomas are also hard to detect with Pap smear tests [14].

Another case leading to an error in diagnosis is performing Pap smear following colposcopy. Given that it takes several months for detectable cell lesions to form again, a false negative is reported as a result of a small number of detectable cells.

However, some of the errors in this field are not associated with the cytology of malignant cells, but with a huge workload, lack of experience, and lack of careful supervision [14].

According to Karla K. Evans et al., laboratory conditions are one of the reasons for error in the diagnosis of cervical cancer. For example, false-negative reports increase and false-positive ones decrease when laboratory samples contain a small amount of malignancy and technicians have little experience [18]. In other words, the technician accuracy reduces when samples containing only a few malignant cells [19].

However, many diagnostic errors are the result of the fact that cytologists are human, and humans make mistakes. The results of a study showed that $3 \%$ of preventable cervical cancers had not been detected because of the errors in Pap smear tests [19].

It is highly important to take greater care in responding to the tests of individuals at high risk for cervical cancer. It is estimated that $60 \%$ to $90 \%$ of cancer cases are associated with inadequate attention and examination of women at high risk for cervical cancer [20-22].

Regarding the above-mentioned cases, to prevent errors in the diagnosis of cervical cancer, Pap smear test is not adequate for proper diagnosis in people with signs of the disease such as bleeding, pain, etc., and also in women at risk for cervical cancer (such as those infected with papillomavirus or those with a family history). Since tumors usually originate from the stromal part of the cervix, their presence cannot be detected by unaffected epithelium and test [15]. Hence, a deep biopsy is essential to providing a definitive and correct report.

In a case report by Ameri et al., despite several negative cytology test results, malignant cells were detected in a deep biopsy and led to a definitive diagnosis [15]. According to Ameri et al., although final diagnosis is only confirming by histology, reviewing pathology slides before definitive treatment reveals notable discrepancies in diagnoses [15]. Other studies have emphasized the importance and accuracy of colposcopy and sampling compared to Pap smear in detecting the early stages of cervical cancer [15, 23].

\section{Errors in the treatment stage}

Although the rate of error is much higher in the diagnosis stage compared to the treatment stage, the errors in this stage should not be overlooked. For example, the majority of radiotherapy cases following hysterectomy are carried out in patients with cervical cancer because of the inadequacy of operation [24]. Yousefi et al., in a cross-sectional analysis of 93 patients, found that inappropriate cervical cancer operation is the major factor in approximately half of the surgeon errors (41\%) [25].

The most common errors in the treatment stage include inadequate pelvic examination before hysterectomy, the absence of a Pap smear test, inappropriate operation despite pathology results, the lack of knowledge about the spread of tumor and involvement of parameters and subsequent inappropriate operation, and leaving behind residual tumor [25]. Thus, pre-treatment evaluation, as well as finding proper treatment way, is necessary for the prevention of adverse effects caused by inappropriate surgical interventions.

\section{Conclusion}

In the present study, the main reasons for medical negligence in the diagnosis and treatment of cervical cancer were cited. It seems that guidelines will be very helpful in preventing errors and informing physicians and pathologists of this field about their likelihood. In addition, since the results indicate a lower possibility of error and sensitivity of colposcopy, colposcopy (where available) or its combination with Pap smear is recommended in screening for cervical cancer. Also, in the treatment stage, more time and attention for pre-treatment evalua- 
tion and proper management could avoid complications such as inappropriate surgical interventions.

\section{Ethical Considerations}

\section{Compliance with ethical guidelines}

There was no ethical considerations to be considered in this letter.

\section{Funding}

This research did not receive any specific grant from funding agencies in the public, commercial, or not-forprofit sectors.

\section{Author's contributions}

All authors contributed in designing, running, and writing all parts of the article.

\section{Conflict of interest}

The authors declared no conflict of interest with respect to this manuscript.

\section{Acknowledgements}

The Authors would thanks Prof. Aghakhani for the guidence of this research.

\section{References}

[1] Fakour F, Atrkar Roshan Z, Shaef SP, Dalil Heyrati SF. [Sensitivity and features of Visual Inspection of Cervix with Acetic Acid (VIA), as a screening test for cervical cancer (Persian)]. Journal of Guilan University of Medical Sciences. 2011; 20(79):49-55.

[2] Steven H. Schafer \& Associates. Delayed diagnosis of cervical cancer. Massachusetts: Lawyers' Global Directory; 2002.

[3] Jena AB, Chandra A, Lakdawalla D, Seabury S. Outcomes of medical malpractice litigation against US physicians. Archives of Internal Medicine. 2012;172(11):892-4. [DOI:10.1001/ archinternmed.2012.1416] [PMID]

[4] Spence AR, Goggin P, Franco EL. Process of care failures in invasive cervical cancer: Systematic review and meta-analysis. Preventive Medicine. 2007; 45(2):93-106. [DOI:10.1016/j. ypmed.2007.06.007] [PMID]

[5] Berthelson L, Mulchan SS, Odland AP, Miller LJ, Mittenberg $\mathrm{W}$. False positive diagnosis of malingering due to the use of multiple effort tests. Brain Injury. 2013; 27(7-8):909-16. [DOI:1 0.3109/02699052.2013.793400] [PMID]
[6] Schneider V, Henry MR, Jimenez-Ayala M, Turnbull LS, Wright TC. Cervical cancer screening, screening errors and reporting. Acta Cytologica. 2001; 45(4):493-8. [DOI:10.1159/000327853] [PMID]

[7] Screening for cancer of the uterine cervix. From the IARC working group on cervical cancer screening and the UICC project group on the evaluation of screening programmes for cancer. IARC Scientific Publications. 1986; (76):1-315. [PMID]

[8] Hakama M, Chamberlain J, Day NE, Miller AB, Prorok PC. Evaluation of screening programmes for gynaecological cancer. British Journal of Cancer. 1985; 52(4):669-73. [DOI:10.1038/bjc.1985.241] [PMID] [PMCID]

[9] Brawley OW, Kramer BS. Cancer screening in theory and in practice. Journal of Clinical Oncology. 2005; 23(2):293-300. [DOI:10.1200/JCO.2005.06.107] [PMID]

[10] Kwa SK. Failure to diagnose cervical cancer: What went wrong? Malaysian Family Physician. 2010; 5(2):109. [PMID] [PMCID]

[11] Perkins RB, Cain JM, Feldman S. Using risk stratification to reduce medical errors in cervical cancer prevention. JAMA Internal Medicine. 2017; 177(10):1411-2. [DOI:10.1001/jamainternmed.2017.3999] [PMID]

[12] Ghaemmaghami F, Hasanzadeh M. [Improper simple hysterectomy in invasive cervical cancer (Persian)]. Cancer Therapy. 2005; 3:357-8.

[13] Rodolakis A, Diakomanolis E, Haidopoulos D, Voulgaris Z, Protopapas A, Makris N, et al. How to avoid suboptimal management of cervical carcinoma by simple hysterectomy. European Journal of Gynaecological Oncology. 1999; 20(56):418-22. [PMID]

[14] DeMay RM. Common problems in Papanicolaou smear interpretation. Archives of Pathology \& Laboratory Medicine. 1997; 121(3):229-38. [PMID]

[15] Ameri M, Memarian A, Behtash N, Karimi Zarchi M. The importance of re-examination with deep biopsies in diagnosing cervical malignancies despite multiple negative pathology reports: A case report. International Journal of Surgery Case Reports. 2015; 14:48-9. [DOI:10.1016/j.ijscr.2015.07.010] [PMID] [PMCID]

[16] Hatem F, Wilbur DC. High grade squamous cervical lesions following negative Papanicolaou smears: False-negative cervical cytology or rapid progression. Diagnostic Cytopathology. 1995; 12(2):135-41. [DOI:10.1002/dc.2840120209] [PMID]

[17] Bahiraee A. [The importance of pap smear in detecting cervical cancer (Persian)]. Hayat. 1999; 5(2):39-45.

[18] Evans KK, Tambouret RH, Evered A, Wilbur DC, Wolfe JM. Prevalence of abnormalities influences cytologists' error rates in screening for cervical cancer. Archives of Pathology \& Laboratory Medicine. 2011; 135(12):1557-60. [DOI:10.5858/ arpa.2010-0739-OA] [PMID] [PMCID]

[19] Derman H. Quality and liability issues with the Papanicolaou smear. Archives of Pathology \& Laboratory Medicine. 1997; 121(3):287-91. [PMID]

[20] Berwick DM. The science of improvement. The Journal of the American Medical Association. 2008; 299(10):1182-4. [DOI:10.1001/jama.299.10.1182] [PMID] 
[21] Miller D. Brain processing of optical input: The perception of visual reality. MD Computing: Computers in Medical Practice. 1994; 11(1):34-42.

[22] Weinert HV, Brill R. Effectiveness of hospital tissue committee in raising surgical standards. The Journal of the American Medical Association. 1952; 150(10):992-6. [DOI:10.1001/ jama.1952.03680100034011] [PMID]

[23] Pourjavad M. [Accuracy of colposcopy and pap smear in screening for cervical cancer (Persian)]. Journal of Mashhad University of Medical Sciences. 1380; 44(72):73-8.

[24] Mahmoodi A, Ghafari P. [Diagnostic value of pap smear in comparison with colposcopy in diagnosis of abnormal cases in women referred to gynecological clinic (Persian)]. Iranian Journal of Obstetrics, Gynecology and Infertility. 2017; 20(10):69-74. [DOI:10.22038/IJOGI.2017.10158]

[25] Yousefi Z, Homaee Shandiz F, Talebian M, Esmaily H, Hasanzadeh M. Surgeons' errors in the management of patients with cervical cancer. Journal of Midwifery and Reproductive Health. 2014; 2(3):165-9. [DOI:10.22038/ JMRH.2014.2849] 